\title{
Morality, consumerism and the internal market in health care
}

\author{
Tom Sorell, Department of Philosophy, University of Essex
}

\begin{abstract}
Unlike the managerially oriented reforms that have brought auditing and accounting into such prominence in the UK National Health Service (NHS), and which seem alien to the culture of the caring professions, consumerist reforms may seem to complement moves towards the acceptance of wide definitions of health, and towards increasing patient autonomy. The empowerment favoured by those who support patient autonomy sounds like the sort of empowerment that is sometimes associated with the patient's charter. For this reason moral criticism of recent NHS reforms may stop short of calling consumerism into question. This, however, would be a mistake: consumerism can be objectionable both within and beyond the health care market.
\end{abstract}

The reforms in the National Health Service reflect two goals of policy-making in the UK. One is the containment of public expenditure; the other is the promotion of personal responsibility, private ownership and entrepreneurship. Over the past fifteen years both goals have been pursued by enlarging the sphere of the market economy, and by popularising one understanding of the individual's place within that economy. Sometimes the sphere of the market economy has been enlarged by privatising public sector activity - selling publicly-owned businesses or contracting out publicly-supplied services. In these cases, different branches of the public sector have been transferred outright to the market economy. In other cases the strategy has been to simulate the market. This is where the NHS fits in. Although its activities continue to be paid for out of general taxation, salary deductions, and, to a much smaller extent, user-charges, their efficiency is determined, at least in theory, by a strict purchaser/provider split modelled on the split between buyer and seller on the open market.

In theory, providers compete for patients, and the competition, at least at the level of hospitals, drives

\section{Key words}

UK National Health Service; internal market; patient's charter; patient's rights; insurance. down prices and raises the quality and supply of treatment. Prices are also supposed to be driven down by freeing up the labour-market in health care, allowing savings to be made according to regional variations in the cost of living and rates of unemployment. For the system to work as intended, the costs of labour and capital and the effectiveness of treatment need to be monitored in great detail, and measures of performance have to be agreed and widely adopted. Many of the moral problems with the internal market arise from what is involved in monitoring cost and measuring performance, rather than from something morally questionable in the policy of getting value for money itself. It is not as if getting value for money is economically important as opposed to morally important. It is both. The NHS discharges an urgent moral obligation to relieve pain and treat disease and to promote fully functioning human life: the more treatment can be provided from fixed or shrinking budgets, the more pain and disease can be treated and full functioning promoted, at least in principle. If the reformed NHS, with its internal market, is more efficient than the NHS with government-imposed cash limits that operated in the early $1980 \mathrm{~s}$, then that is an argument - a moral argument as well as an economic argument - for the reformed NHS.

Yet the morally important goal of making budgets stretch further may itself have moral costs. The NHS relies on the skills and commitment of a vast number of health care professionals and allied workers. Maintaining their commitment and morale is expensive, and the main factor pushing this cost upwards is rarely simple selfishness. When the poor pay of some NHS employees is kept low because public spending targets require it, that is a sign that people whose work is morally valuable are themselves the victims of a failure of distributive justice. The more the relief of pain and suffering costs, however, the less relief can be provided within limited budgets. Or at least, the less can be provided unless waste is rife. It is unlikely to be clear whether waste is rife unless the costs of providing health care are established, and unless the health care provided is known to be effective. But here, too, finding out costs and deciding on effectiveness is itself costly - costly in time and resources, and costly in morale. Specialist skills are required to adapt 
accounting and audit measures to health care. These skills are likely to be bought at rates of pay that dwarf the pay of those who are closest to the patient and at times responsible for the patient's life and death. Again, the diversion of health service money into accounting and audit is likely to appear self-defeating, since it depletes the funds that auditing and accounting are supposed to allow to be used better for health care. The effort and resources put into audit and accounting may make it appear as if the goal of economic efficiency is hijacking the health service and making the doctors and nurses secondary to the managers. What is perhaps worse, the measures used in audit are likely to be disputed, so that energy that ought to be channelled into health care is diverted into argument about projections and spreadsheets. Finally, medical staff may not only find the auditing and managerial culture alien; they may not have the skills or inclination to fall in with its demands. As a result, they may feel demoralised enough, or alienated enough, to leave health care altogether, thereby putting out of circulation skills that cost the state a great deal to teach. The British Medical Association has recently reported an alarming increase in the number of GPs leaving medicine, and this has occurred concurrently with increased difficulties in recruiting newly qualified doctors into general practice. The economic cost of demoralised, expensively trained people is also a moral cost, since it is another instance of resources being taken away from the promotion of wellbeing.

\section{Moral costs}

Against this background the economic and related moral costs of reform may cancel out the economic benefits of increased efficiency, desirable as those benefits are. Even if the costs are outweighed by the benefits, the economic and moral complexity of realising the benefits is hard to exaggerate. And there are further, more specific economic and moral costs, arising from the way the reforms have been implemented in practice. Some of these have been pointed out in the recent literature by Alan Maynard, ${ }^{1}$ Calum Paton, ${ }^{2}$ and Robert Royce, ${ }^{1}$ and I do not propose to cover the same ground. Instead, I want to turn to the other goal of public policy-making that I am claiming is behind the NHS reforms: namely, the goals of promoting personal responsibility, private ownership and so forth. This goal has been pursued by popularising a certain understanding of the individual's relation to the market: on the one hand, an individual is dependent on the market for his or her income and is under an obligation not to set his or her wage demands too high; on the other hand, the individual is encouraged to be a an exacting purchaser of services from the market, and to make choices that are as informed as possible. Call this the consumerist role of the individual. The NHS reforms engage this role through a patient's charter, just as government reforms else- where in the public sector engage this role through other charters. These charters lay out the conditions? of service that consumers are either guaranteed or can usually expect the public sector to provide, sometimes? backed up by financial compensation in the event of non-performance.

Unlike the managerially oriented reforms that? have brought auditing and accounting into such $\mathscr{\Phi}^{\circ}$ prominence in the NHS, and which seem alien tow the culture of the caring professions, consumerist reforms may seem to complement moves that arebeing made towards the acceptance of wide defini- $\vec{\omega}$ tions of health, and towards increasing patient? autonomy. Certainly the rhetoric of consumerism with its emphasis on the words "choice" andin "freedom" harmonises with talk of making treat- - N ment more sensitive to the choices of the patient ${ }^{4}$ and harmonises also with talk of empowering patients by giving them more information. The empowerment favoured by those who support $\vec{\longrightarrow}$ patient autonomy sounds like the sort of empower=o ment consumer groups often talk about. And to the extent that power seems to be transferred under thes NHS reforms from hospital consultants to a wider. variety of providers of primary care and patients, the reforms can give the impression of marching in steps with measures that opponents of the government advocate on moral rather than economic grounds. For this reason moral criticism of the NHS reforms may stop short of calling consumerism into question. This, however, would be a mistake. As I shall nows try to show, consumerism can be objectionable both within and beyond the health care market.

I

We can say that a policy of providing a good or? service is consumerist when the receiver of the goodo or service is regarded primarily as a paying customer, and when the provider subscribes to the precept that that the customer is always right, or that the $>$ customer is usually right, or that the customer has to․ be treated as if he were always right. Treating then customer as if he is always right does not just mear being disposed to concede to the customer when there is a dispute between buyer and seller over whow is right; it means gearing commercial practice to things consumers are known to like, such as paying as little as possible or paying as late as possible.

It is hard not to have some sympathy with con - ? sumerism, for consumerist policies often benefit us when we are at the receiving end; and in the Western world practically everyone is at the receiving end of goods and services as a paying customer several times a day. Again, in the free market, sellers are dependene on buyers who, if the market is working well, are always free to choose the goods or services of a competitor. In order to get a competitive edge in such at. market, a seller may have to use more than the strategy? of keeping the price low. The seller may have to 
accommodate the buyer in other ways, for example, in relation to speed of delivery or terms of credit. Consumerism can thus be in the interest of sellers as well as buyers in a competitive market. In the form of consumer protection regulations or consumer advocacy, consumerism may also be a justified response to the inequality of sellers and buyers in some markets. The inequality may consist of an asymmetry of knowledge, or of financial strength, so that the buyer is at risk of being manipulated into purchasing, or having to suffer serious damage or loss when something goes wrong. So far, so good for consumerism. Nevertheless, it is not hard to think of cases where the customer is not right, and where catering to the customer's wishes might be cruel to a third party - as in the case of the market for videos showing sexual assault - or unjust to the provider of a service.

\section{Small business}

Some clear cases of unjust treatment of providers by consumers come from the sphere of small business. ${ }^{5}$ In small business buyer and seller need not be very different from one another in financial strength or sophistication, so that the usual presumption in favour of the customer's being the weaker party falls away, as does one ground for consumerism. Even where the seller is big and profitable, it is possible for the customer to take undue advantage, and therefore act unjustly. For example, if a shopper buys a lamp or a rug on a whim and then becomes disenchanted with it though it is not faulty, it can happen that he demands his money back. Shoppers may even invent flaws or claim that they were pressured into buying when in fact they weren't. In such cases, the fact that the shop is large and profitable and can afford to take back the goods does not make it right for the shop to be asked to do so. It is no more right than if the refund were demanded for negligently purchased goods from a kiosk on the verge of bankruptcy. Negligent shoppers cannot even be let off the hook entirely when the business they want the refund from has a consumerist policy guaranteeing refunds. For example, in the UK, the department store group John Lewis has a policy of giving refunds for goods so long as the request for a refund is not grossly unreasonable. This condition might be met where the imprudent shopper returns the rug or lamp. But that a refund for the lamp or rug is permissible under the policy does not mean that the shopper was not negligent after all. It is like the case where one driver carelessly runs into another car whose owner happens to be forgiving. The forgiveness does not cancel out the negligence; and neither does a generous refund policy make it all right to ask for a refund for something that works perfectly well but was bought thoughtlessly.

Patients can also be negligent and overdemanding, and clutch at consumerist policies to make themselves appear to be in the right. If they demand to be seen by a GP without an appointment or call out a doctor in the middle of the night without giving much thought to whether their condition is serious, then they are going in for a kind of behaviour that compares closely with unreasonable behaviour in the commercial world, behaviour we have only to be reminded of to see that the customer is not always right. Again, if a patient turns from one general practice register to another because the first practice wouldn't let him see a doctor without an appointment, or because the first practice had too many women doctors, or because he did not like the tone of voice the doctor used when pointing out the consequences of continued heavy smoking, the patient may very well be unreasonable, and it is unreasonable to encourage unreasonable patients to think that they are always or usually right, just as it is unreasonable to encourage unreasonable John Lewis customers to believe that they are always right.

We should also consider unreasonable lengths that providers of services may be asked to go to in getting or retaining business or in satisfying a customer or patient. Accountants are sometimes given to understand by clients that they must disguise or condone a financial irregularity in order to retain an account; doctors may be asked to provide a medical excuse for an absence from work of a perfectly healthy patient, or to back up a claim for compensation with appropriate medical evidence. Even where it would look like disloyalty not to back up the patient, even where not to back up the patient would lead to some therapeutic setback, the misrepresentation involved might make it wrong to agree to the request. And if the patient were supported, the justification there might be for doing so would have to come from the consequences for patient wellbeing of not doing so, rather than from the status of patient as consumer.

A different sort of case occurs where the patient requires treatment that would have been unnecessary if earlier medical advice had been followed, or requires treatment that will only have a negligible benefit unless the patient changes his ways, for example by eating or drinking or jogging less. Here the patient is not asking the doctor do anything shady, but there are medical grounds against complying unless the patient does his part as well. If the patient refuses to do his part, or believes that the patient's part consists of receiving treatment full stop and not cooperating with preventive measures, then perhaps the doctor goes too far if he meekly treats the patient and the patient continues to jog, smoke or eat as much as before. That the patient might have his part to perform, his responsibilities in the medical relationship, is at least not emphasised in the UK patient's charter: it is all about patient rights and expectations.

\section{II}

Just as consumerism in the commercial context sometimes obscures or even excuses the overdemandingness of some consumers, so consumerism 
adapted to patients may obscure or appear to excuse the negligence and overdemandingness of patients. But second thoughts about consumerism cannot stop there, because there are reasons to think that patients are not consumers at all, or consumers of too unusual a kind, to be covered by any simple consumerist policy. First, the typical consumer is assumed to be adult, healthy, able to reason, informed or in a position to become informed, and solvent. A patient need be none of these things at the point at which treatment is necessary or has to be thought about. Second, an effective choice of a treatment or of a doctor may require a grasp of specialised information that even a rational, healthy adult lacks the training to grasp. It usually takes less to make an effective choice of a rug or lamp. Third, within the context of the National Health Service the patient need not be a paying customer in any sense. When he is a paying customer in some sense, that is, when he has a deduction made from his salary every month, the payments are unrelated to the cost of a specific treatment he receives if he receives any treatment at all. The price of treatment is usually entirely unknown to the patient, and is not a factor in his decisions about treatment, though it may be a factor in decisions about what treatments are proposed to him by his doctor. Finally, the people or institutions that the treatment is bought from do not face bankruptcy or even a significant loss of earnings if the patient is dissatisfied. In all of these respects, patients are either unlike consumers, or else, because of the insensitivity of their behaviour to price, not enough like ordinary buyers in the market to be called consumers of the same kind as ordinary buyers.

\section{No-claims bonus}

Even when the users of the health service have paid for it through their general taxes or deductions from their salaries, it is misleading to describe them as buyers of a service on the model of retail purchasers of building work or a telephone connection. They are better described as contributors to a compulsory mass health-insurance pool. Participation in the mass pool is compulsory in the sense that those who have the means to contribute and are not in the black economy are obliged to contribute. But contributors do not necessarily use the service, and users are not necessarily contributors. What is more, contributions are according to income or ability to pay rather than according to health risk. These facts distinguish NHS contributions even from contributions to other insurance pools. Unlike purchasers of commercial health insurance, contributors to the NHS do not pay according to lifestyles or genetic histories. They do not pay according to age or where they live or what they do for a living. This means that some users, even paying users, are heavily subsidised by others. Or, in other words, many contributors pay heavily for other people's risks and other people's treatment. Some contributors pay for that other treatment knowing they will never use the NHS? themselves. It is the use of the service rather than payment for it that entitles one to enforce expecta $\stackrel{\text { ? }}{7}$ tions about the standard of service in the NHS. This? makes the consumerism of the NHS very different흐 from consumerism of the ordinary kind.

Not only does the NHS substitute a non-economic category of user or patient for that of consumer; its shuns policies that are essential to consumerism in the insurance industry. A leading consumerist practice inthe insurance industry is the award of a no-claimsw bonus on premiums. People who have no record of drawing on an insurance pool for automobile collisions, for example, are allowed to make smaller and smaller annual payments; when they do make a claim; this bonus is lost. Now commercial health insurance cannot operate quite the same sort of no-claims policyo as car insurance, since the risk of having to draw on the pool increases with age and so with the length of time there has been no claim made on the policy. $\mathrm{A}$. health insurance policy that cut premiums to the nonclaiming twenty-year-old until they were very lowe indeed, and then kept them at that level until there was a claim, could not sustain the big payouts thato would be required when the policy-holder who hads never yet claimed reached an age associated witho expensive illnesses. But commercial health insuranceo premiums are adjusted to reflect relatively low-risk lifestyles and occupations. From the angle of the $\overrightarrow{0}$ private health insurance market, low-risk people who3 pay the same as high-risk people into the NHS pool are not getting their due as customers (a premium? that rewards low-risk policy-holders), while those who never pay and always use the NHS (sometimes. because they smoke and drink far more than doctors? advise) are getting a free ride at the expense of paying non-users. From the angle of the commercial market, it is the free riders who should be paying, or perhaps who should be excluded from insurance altogether, since they do nothing to lower their health risks.

\section{Principle of solidarity}

If one finds this way of thinking repellent, because one subscribes to the principle of providing treatment ${ }^{\omega}$ according to need and not according to means, then one has also got to consider whether insurance con은 sumerism, which generates this way of thinking, is really at home in the NHS context, even though ${ }_{-}^{-}$ payments for the NHS go into an insurance pool. It maybe that in the NHS, as opposed to the commer-市 cial health insurance funds, a principle of solidarity between paying non-users and non-paying users and? everybody in between has to be introduced. It may be that a solidarity principle has also got to operate inf environments where there is only commercial healthe insurance and people who would normally be excluded from the pool because of the burden they? would impose on low-risk payers would thereby have 
no protection from catastrophic loss of income and disability. It may be that where there is no other way of providing medical help, it being a very fundamental component of wellbeing, consumerist thinking has got to lapse. If that is right, and if the kind of good medical help is for a human being provides a direct argument for having an insurance scheme geared to solidarity, it is unclear that any further moral illumination or power is added by talking of that human being as a buyer or consumer of a service. The unrevamped concept of a patient or the concept of a potential patient carries all the content one needs.

The principle of solidarity needs a very different perspective from the perspective of the patient's charter. It does not focus narrowly on the relation of patients to providers, but on relations between patients, and between patients and payers where these groups are different. It would be interesting to consider what entries a patient's charter might have that reflected these relations. People who eat or drink themselves into hospital might have shortcomings as fellow contributors to a solidarity pool; and people who use up resources for conditions that are not obviously health risks, such as infertility, might also flout the principle of treatment according to need. Of course, other things are paid for out of the insurance pool than medical conditions, for example the very large salaries of consultants and relocation expenses for managers. Would people feel as comfortable drawing these things from what they regard as a solidarity fund, albeit one they contribute to, as they might drawing them from wealthy patients' fees on the private market?

\section{Health and wealth}

I have been arguing that consumerism tends to misrepresent the NHS and the position of users within it. Patients are certainly not the only ones with rights, and they have responsibilities to others in the NHS, not only to the doctors, but also to the paying non-users or the paying light users. The paying nonusers and the paying light users, for their part, are not necessarily being taken advantage of by the others, since the good they are subsidising for the heavy users is one that the people cannot do without. This is why solidarity is in order. It may be a kind of bad luck that one is in a position to be a heavy payer at a time institutions exist to exact the payment from you. But it is not bad luck to be in the position of being a heavy payer, or for one's resources to be used to relieve the need for so basic a good. For in order to be a heavy payer, one normally needs health and wealth, and one's wealth is normally far from exhausted when one subsidises other people's health care through an insurance pool. From the perspective of solidarity, the heavy non-users are lucky to be at such low risk and have a greater ability, as a result, to gain the income from which their contributions are drawn. From a consumerist angle, on the other hand, the heavy-paying non-claimants in an insurance pool are heavily exploited: they are being charged too much for protection against a small risk of ever having draw upon the pool themselves.

It might be objected that I have been too hard on consumerism, since in the NHS context the effect of it, or at least the intended effect, is the morally creditable one of getting providers to think more and more about the wishes of patients, and less and less about making life easier for themselves. It might be thought that far from needing criticism, consumerism actually promotes treatment that shows patients more respect in the moralist's sense of "respect". Again, when the consumer is not the individual patient but the GP practice or the health authority, the consumerism of the reformed NHS can have the effect of producing a greater amount of synergy between providers and purchasers of a service, with likely therapeutic benefits for patients. Surely this, too, must constitute a moral improvement over the old NHS?

I concede that the purchaser/provider split may bring about more coordination among GPs, hospitals and health authorities through the discipline of financial penalties for those who are careless of purchaser choice, but I doubt that consumerism is the right medium for increasing respect for patients in the sense of "respect" that is familiar in moral theory. The standard basis in moral theory for moral respect - namely the humanity or personhood of the patient - is independent of, and logically prior to, any role a patient has as user or consumer of a service. Moreover, treating someone primarily as a user or purchaser of a service need not reinforce respect for persons, since it might emphasise the economic value that a patient offers - the increase in practice size and income - rather than the value of a person. Again, in morality respect is a two-way street, as appropriate, other things being equal, to those who give as to those who receive treatment. But in consumerism purchaser and provider are precisely not equal. It is the customer who gets precedence - in return for economic gain; and quite a lot of latitude is allowed to consumers in pursuing and defending their own interests against providers or sellers. Finally, consumerism is usually unconcerned with responsibilities of users or consumers to one another, and it tends to ignore all but the relations affecting economic competition between providers. In the NHS context, however, users have responsibilities to one another, and so do competing providers. Users have responsibilities to other users not to overburden the NHS, for example; and providers have responsibilities not to pursue competition so aggressively that small regional hospitals or valuable centres of research are wiped out.

Tom Sorell, BA, BPhil, DPhil, is Professor of Philosophy at Essex University and Fellow in Ethics at Harvard University, Cambridge, USA. 


\section{References}

1 Maynard A. Can competition enhance efficiency in health care? Lessons from the reform of the UK National Health Service. Social Science and Medicine 1994; 39: 1433-45.

2 Paton C. Present dangers and future threats: some perverse incentives in the NHS reforms. British Medical fournal 1995; 310: 1245-8.
3 Royce R. Observations on the NHS internal market: will the dodo get the last laugh? British Medical fournal 1995; 311: 431-3.

4 The harmony is perhaps only superficial. For criticism of this rhetoric see Sorell T, Hendry J. Business ethics. Oxford: Butterworth-Heinemann, 1994: ch 7.

5 Sorell $\mathrm{T}$. The customer is not always right. fournal of Business Ethics 1994; 13: 913-8.

\section{News and notes}

\section{Teaching research ethics}

The fourth annual workshop on teaching research ethics will be held from June $25-28$ this year at Indiana University.

Presentations will include: Shaping scientific thought: ambiguities in the practice of science; Investigating allegations of scientific misconduct; Conflicts of interest in research; Using animal subjects in research, and Responsible data management.

For further information please contact: Kenneth D Pimple, "Teaching Research Ethics", Project Director, Poynter Center, Indiana University, 410 North Park Avenue, Bloomington IN 47405; (812) 855-0261; fax: 855 3315; pimple@indiana.edu.http://www.indiana. edu/ $\sim$ poynter/index.html

\section{News and notes}

\section{Contemporary challenges in health care ethics}

The Kennedy Institute of Ethics is offering an intensive course designed to address the most challenging topics in health care ethics. The course provides the opportunity for participants from other fields and disciplines to come together for a few days to explore the theoretical framework and practical issues of bioethics with a distinguished faculty.

Course participants receive a one-year membership to the Kennedy Institute Members' programme; membership benefits include subscription to the Kennedy Institute of Ethics fournal and invitation to the annual members' symposium. Continuing medical education credit and continuing education units are available for each course.

For further information please contact Emily Wilson: tel: (202) 687-6771; fax: (202) 687-8089. KICOURSE@gunet.georgetown.edu. Kennedy Institute of Ethics, Box 571212, Georgetown University, Washington, DC 20057-1212, USA.

\section{News and notes}

\section{Call for papers}

A conference entitled Values in Psychiatric Nosology: $A$ Conference for Philosophers and Mental Health Professionals will be held from December 4-6, 1997 (tentative), in Dallas, Texas, USA.

Papers are being called for; the submission deadline is August 11997.

The University of Texas Southwestern Medical Center at Dallas, the Cary M Maguire Center for Ethics and Public Responsibility at Southern Methodist University, and the Association for the Advancement of Philosophy and Psychiatry are sponsoring the conference, supported by a grant from the Greenwall Foundation.

The conference aims: (1) to provide an intimate forum for an exchange of viewpoints about the role of values in psychiatric classification; (2) to improve the quality of future diagnostic classifications through an enhanced awareness of value issues; and (3) to make concrete and specific suggestions to psychiatric nosologists about how value-related nosological problems can be addressed in future editions of the DSM or ICD. A selection of the conference papers and discussion will be published in book form.

For further information and manuscript requirements contact: Linda Muncy, Administrative Co-ordinator, Values and Psychiatric Nosology Conference, Department of Psychiatry, UT Southwestern, 5323 Harry Hines Boulevard, Dallas, TX 75235-9070, USA. Telephone: 214648 3390; facsimile: 2146487980 ; e-mail:<LMUNCY@mednet,swmed.edu> 